\title{
Dietary creatine supplementation does not affect some haematological indices, or indices of muscle damage and hepatic and renal function
}

\author{
Tristan M Robinson, Dean A Sewell, Anna Casey, Gery Steenge, Paul L Greenhaff
}

\begin{abstract}
Background-The use of creatine $(\mathrm{Cr})$ as a nutritional supplement to aid athletic performance has gained widespread popularity among athletes. However, concerns have recently been expressed over potentially harmful effects of short and long term $\mathrm{Cr}$ supplementation on health. Methods-Forty eight young healthy subjects were randomly allocated to three experimental protocols aimed at elucidating any potential health risks associated with five days ( $20 \mathrm{~g} /$ day) to nine weeks ( 3 g/day) of $\mathrm{Cr}$ supplementation. Venous blood samples were collected before and after periods of $\mathrm{Cr}$ supplementation and were analysed for some haematological indices, and for indices of hepatic, muscular, and renal dysfunction.

Findings-All measured indices were well within their respective normal range at all times. Serum creatinine concentration tended to be increased the day after $\mathrm{Cr}$ supplementation. However, values had returned to baseline six weeks after the cessation of supplementation. These increases were probably attributable to increased creatinine production rather than renal dysfunction. No indication of impairment to the haematological indices measured, hepatic function, or muscle damage was apparent after $\mathrm{Cr}$ supplementation.
\end{abstract}

Interpretation-These data provide evidence that there are no obvious adverse effects of acute or more chronic $\mathrm{Cr}$ supplementation on the haematological indices measured, nor on hepatic, muscle, and renal function. Therefore there is no apparent health risk associated with $\mathrm{Cr}$ supplementation to healthy people when it is ingested in quantities that have been scientifically proven to increase muscle $\mathrm{Cr}$ stores.

(Br F Sports Med 2000;34:284-288)

Keywords: creatine supplementation; kidney; liver; blood; muscle; exercise; metabolism

Creatine $(\mathrm{Cr})$ metabolism is of interest because of its pivotal role in energy transduction in cells with fluctuating energy demands. Current interests in $\mathrm{Cr}$ as a nutritional supplement include its use as an ergogenic aid ${ }^{1}$ and its potential therapeutic role in conditions such as cardiac insufficiency. ${ }^{2}$ In recent years $\mathrm{Cr}$ supplementation has been shown by several laboratories to have a positive effect on the performance of repeated bouts of short lasting maximal exercise, ${ }^{1-5}$ the magnitude of which has been associated with the extent of muscle Cr accumulation. ${ }^{5}$ As a result, $\mathrm{Cr}$ has become a very popular dietary supplement used by amateur and professional athletes, with sales in the United States totalling $\$ 100 \mathrm{~m}(£ 60 \mathrm{~m})$ during $1997 .^{6}$

In most studies, a dosing regimen of $20 \mathrm{~g} \mathrm{Cr}$ a day for five days ${ }^{78}$ has been used to "load" muscles with Cr. The single $5 \mathrm{~g}$ dose used in this regimen can increase plasma $\mathrm{Cr}$ concentration by up to 13-fold, which then remains significantly higher than basal concentration for three hours. ${ }^{9}$ It is believed that this promotes the transport of $\mathrm{Cr}$ into muscle and, after five days of supplementation, results in about a $25 \mathrm{mmol} / \mathrm{kg}$ dry mass increase in muscle total $\mathrm{Cr}$ (TCr). The muscle TCr concentrations achieved by this regimen can be maintained by continuing $\mathrm{Cr}$ ingestion at a "maintenance dose" of about 2 g every day, which represents the average rate of daily $\mathrm{Cr}$ degradation to creatinine. ${ }^{10}$

Anecdotal opinions have been expressed ${ }^{611}$ about the potential effect of ingested $\mathrm{Cr}$ on aspects of health, such as muscle cramping, muscle-tendon injury, and renal dysfunction. Opinions such as these, however, have not been supported with scientific evidence, other than two recent case reports of renal dysfunction accompanying oral creatine supplementation, ${ }^{12}{ }^{13}$ one of which was in a patient with pre-existing kidney disease. ${ }^{12}$ Despite its apparent widespread use by athletes, ${ }^{14}$ there is little published evidence of the effects of $\mathrm{Cr}$ supplementation on health indices, such as haematological, hepatic, and renal function, or muscle damage. The aim of this study therefore was to obtain information on such indices in young healthy adult subjects, before and after a typical regimen of " $\mathrm{Cr}$ loading", and also after a typical Cr loading and eight week "maintenance" regimen. ${ }^{8}$

\section{Methods}

SUBJECTS

Forty eight healthy subjects volunteered to take part in the series of experiments. None reported any history of kidney or liver related illness. All subjects regularly undertook some form of exercise but none was highly trained. Before inclusion, informed written consent was obtained from all of them, and ethical approval was obtained from the Nottingham University Medical School ethics committee. 
Table 1 Summary of experimental groups and protocol

\begin{tabular}{|c|c|c|c|}
\hline Experimental group & No and sex & Summary of treatment & Time of sampling after supplementation \\
\hline $\mathrm{Cr}_{\mathrm{LOAD}}$ & 7 , men & $5 \mathrm{~g} \mathrm{Cr}+500 \mathrm{ml} \mathrm{CHO}$ drink, 4 times daily, 5 days & 1 day \\
\hline $\mathrm{P}_{\text {LOAD }}$ & 7 , men & $500 \mathrm{ml} \mathrm{CHO}$ drink, 4 times daily, 5 days & 1 day \\
\hline $\mathrm{Cr}_{\mathrm{LOAD}+6}$ & 6 , men & $5 \mathrm{~g} \mathrm{Cr}+1 \mathrm{~g}$ glucose, 4 times daily, 5 days & 6 weeks \\
\hline $\mathrm{P}_{\mathrm{LOAD}+6}^{\mathrm{LOAD+6}}$ & 6,3 men, 3 women & $6 \mathrm{~g}$ glucose, 4 times daily, 5 days & 6 weeks \\
\hline $\mathrm{Cr}_{\text {MAINT }}$ & 7 , women & $5 \mathrm{~g} \mathrm{Cr}, 4$ times daily, 5 days followed by $3 \mathrm{~g} \mathrm{Cr}$ daily, 8 weeks & 1 day \\
\hline $\mathrm{Cr}_{\text {MAINT+EX }}$ & 9, women & $\begin{array}{l}5 \mathrm{~g} \mathrm{Cr}, 4 \text { times daily, } 5 \text { days followed by } 3 \mathrm{~g} \mathrm{Cr} \text { daily, } 8 \text { weeks }+ \\
\text { resistance exercise training }\end{array}$ & 1 day \\
\hline $\mathrm{P}_{\text {MAINT+EX }}$ & 6 , women & $\begin{array}{l}5 \mathrm{~g} \text { glucose, } 4 \text { times daily, } 5 \text { days followed by } 3 \text { g glucose daily, } 8 \\
\text { weeks }+ \text { resistance exercise training }\end{array}$ & 1 day \\
\hline
\end{tabular}

EXPERIMENTAL GROUPS

The 48 subjects were divided randomly into seven experimental groups to examine two different aspects of $\mathrm{Cr}$ supplementation (table 1).

Effects of a Cr loading regimen

Group $\mathrm{Cr}_{\text {LOAD }}$ consisted of seven men (mean (SD) age 23 (4) years and body mass index (BMI) $22.4(2.1) \mathrm{kg} / \mathrm{m}^{2}$ ) who ingested $5 \mathrm{~g} \mathrm{Cr}$ dissolved in a warm drink followed by $500 \mathrm{ml}$ of a carbohydrate-containing solution four times a day for five days. This regimen was used because we have previously shown it to augment muscle $\mathrm{Cr}$ accumulation by about $60 \%$ more during five days of $\mathrm{Cr}$ loading than when $\mathrm{Cr}$ alone was ingested. ${ }^{15}$ This increase in $\mathrm{Cr}$ accumulation has been attributed to insulin augmenting sodium dependent muscle $\mathrm{Cr}$ transport..$^{15}$ Blood samples for analysis were obtained the day before supplement ingestion began and the day after the ingestion regimen had been completed.

Group $\mathrm{P}_{\text {LOAD }}$ (a placebo group) consisted of seven men (age 24 (5) years; BMI 21.3 (0.9) $\mathrm{kg} / \mathrm{m}^{2}$ ) who ingested $500 \mathrm{ml}$ of a carbohydratecontaining solution four times a day for five days. Blood samples for analysis were obtained as for the $\mathrm{Cr}_{\mathrm{LOAD}}$ group.

Group $\mathrm{Cr}_{\mathrm{LOAD}+6}$ consisted of six men (age 24 (3) years; BMI $25.6(6.3) \mathrm{kg} / \mathrm{m}^{2}$ ) who ingested $5 \mathrm{~g} \mathrm{Cr}$ plus $1 \mathrm{~g}$ glucose dissolved in a warm drink four times a day for five days. Blood samples for analysis were obtained before the start of supplementation and six weeks after the ingestion regimen had been completed, when muscle $\mathrm{Cr}$ stores would be expected to have returned to levels found before supplementation. ${ }^{8}$

Group $\mathrm{P}_{\mathrm{LOAD}+6}$ (a placebo group) consisted of six subjects (age 22 (2) years; BMI 21.7 (2.0) $\mathrm{kg} / \mathrm{m}^{2}$; three men), who ingested $6 \mathrm{~g}$ glucose dissolved in a warm drink four times a day for five days. Blood samples for analysis were obtained as for the $\mathrm{Cr}_{\mathrm{LOAD}+6}$ group.

\section{Effects of Cr loading and an eight week}

maintenance regimen

Group $\mathrm{Cr}_{\text {MAINT }}$ consisted of seven women (age 26 (8) years; BMI $23.3(1.9) \mathrm{kg} / \mathrm{m}^{2}$ ) who ingested a loading dose of $5 \mathrm{~g} \mathrm{Cr}$ dissolved in a warm drink four times a day for five days, and who then maintained an intake of $3 \mathrm{~g} \mathrm{Cr}$ in a warm drink, once a day for eight weeks. During this period, all subjects refrained from performing strenuous exercise. Blood samples for analysis were obtained before supplement ingestion on the first day of the loading dose and on the day after the maintenance regimen had been completed.

Group $\mathrm{Cr}_{\text {MAINT+EX }}$ consisted of nine women (age 27 (6) years; BMI $23.4(3.2) \mathrm{kg} / \mathrm{m}^{2}$ ) who ingested a loading dose of $5 \mathrm{~g} \mathrm{Cr}$ dissolved in a warm drink four times a day for five days, and who then maintained an intake of $3 \mathrm{~g} \mathrm{Cr}$ in a warm drink, once a day for eight weeks. During the eight week maintenance period, subjects engaged in a resistance training programme. This exercise programme was used to create similar conditions to those of subjects who ingest $\mathrm{Cr}$ during periods of training to improve athletic performance, as anecdotal reports have been made of muscle cramps occurring during Cr supplementation and training. ${ }^{11}$ The training programme involved three one hour supervised resistance training sessions each week. Blood samples for analysis were obtained as for the $\mathrm{Cr}_{\text {MAINT }}$ group.

Group $\mathrm{P}_{\text {MAINT+EX }}$ (a placebo group) consisted of six women (age 28 (5) years; BMI 24.5 (3.6) $\mathrm{kg} / \mathrm{m}^{2}$ ) who ingested a "loading dose" of $5 \mathrm{~g}$ of a glucose polymer dissolved in a warm drink four times a day for five days, and who then maintained an intake of $3 \mathrm{~g}$ of glucose polymer in a warm drink, once a day for eight weeks. During the eight week supplementation period subjects engaged in a resistance training programme identical with that used by subjects in the $\mathrm{Cr}_{\text {MAINT+Ex }}$ group. Blood samples for analysis were obtained as for the $\mathrm{Cr}_{\text {MAINT }}$ group.

\section{Supplement formulations}

Subjects in the $\mathrm{Cr}_{\mathrm{LOAD}+6}, \mathrm{P}_{\mathrm{LOAD}+6}, \mathrm{Cr}_{\text {MAINT }}$, $\mathrm{Cr}_{\text {MAINT+EX }}$, and $\mathrm{P}_{\text {MAINT+EX }}$ groups were provided with supplements in a double blind manner. During the five day "loading dose" period, subjects in all groups were asked to ingest their supplement dose at four regularly spaced intervals evenly distributed throughout each day. During the eight week "maintenance dose", subjects ingested their daily supplement dose at the same time each day. All $\mathrm{Cr}$ was given in its monohydrate powder form (Experimental and Applied Science, Golden, Colorado, USA). The glucose polymer was provided as dextrose powder, and the carbohydrate drink as a commercially available solution (Lucozade; about $18.5 \%$ (w/v) glucose and simple sugars; SmithKline Beecham, Coleford, Gloucestershire, UK).

\section{SAMPLING PROTOCOL}

Subjects reported to the laboratory on the morning of the experiments after an overnight fast, having abstained from alcohol consumption and strenuous exercise during the previous 
Table 2 Normal range $e^{16}$ and mean (SD) values of haematological indices and indices of muscle damage and hepatic and renal function before (all groups), immediately after ( $C r_{L O A D}, P_{L O A D}$ groups), and six weeks after $\left(C r_{L O A D+6}, P_{L O A D+6}\right.$ groups) five days of creatine (Cr) or placebo ( $P$ ) ingestion

\begin{tabular}{|c|c|c|c|c|c|c|c|c|c|}
\hline \multirow[b]{2}{*}{ Clinical index } & \multirow[b]{2}{*}{ Normal range } & \multicolumn{2}{|l|}{$C r_{L O A D}$ group } & \multicolumn{2}{|l|}{$P_{L O A D}$ group } & \multicolumn{2}{|c|}{$C r_{L O A D+6}$ group } & \multicolumn{2}{|c|}{$P_{L O A D+6}$ group } \\
\hline & & Pre & Post & Pre & Post & Pre & 6 weeks & Pre & 6 weeks \\
\hline Sodium & $135-145$ & $141(2)$ & $141(1)$ & $141(2)$ & $142(1)$ & $139(1)$ & $141(1)^{\star}$ & $138(1)$ & $140(2)$ \\
\hline Potassium & $3.5-5.0$ & $4.0(0.4)$ & $3.9(0.3)$ & $4.0(0.3)$ & $4.3(0.4)$ & $4.0(0.2)$ & $4.0(0.3)$ & $4.1(0.2)$ & $4.0(0.2)$ \\
\hline Urea & $2.5-7.0$ & $4.4(1.1)$ & $3.8(1.3)$ & $4.9(1.0)$ & $3.5(1.1) \ddagger$ & $4.1(0.4)$ & $5.3(0.6) \dagger$ & $4.7(0.7)$ & $4.2(0.7)$ \\
\hline Creatinine & $60-130$ & $88(15)$ & $112(30)$ & $96(14)$ & $92(18)$ & $103(10)$ & $105(10)$ & $82(8)$ & $85(12)$ \\
\hline GGT & $0-65$ & $20(5)$ & $19(4)$ & $24(7)$ & $23(8)$ & $27(7)$ & $27(9)$ & $21(7)$ & $22(6)$ \\
\hline $\mathrm{AP}$ & $30-110$ & 67 (17) & $72(17)$ & $71(16)$ & $72(18)$ & $72(9)$ & $72(13)$ & $64(15)$ & $61(15)$ \\
\hline ALT & $5-40$ & $25(7)$ & $24(7)$ & $22(3)$ & $25(4)$ & $27(8)$ & $30(7)$ & $19(3)$ & $21(3)$ \\
\hline Albumin & $35-50$ & $44(3)$ & $43(2)$ & $44(2)$ & $44(2)$ & $47(4)$ & $45(1)$ & $47(2)$ & $45(2) \ddagger$ \\
\hline Bilirubin & $5-17$ & $14(5)$ & $12(6)$ & $16(3)$ & $12(3) \dagger$ & $12(2)$ & $10(2)$ & $12(4)$ & $10(3)$ \\
\hline CK & Up to 200 & Not measured & & Not measured & & $152(85)$ & $127(34)$ & $92(42)$ & $123(108)$ \\
\hline $\mathrm{Hb}$ & $11.5-18.0$ & $14.0(0.8)$ & $14.0(0.9)$ & $14.6(0.3)$ & $14.4(0.6)$ & $14.9(0.8)$ & $14.7(0.6)$ & $13.9(1.3)$ & $13.4(1.1)$ \\
\hline WBC & $4.0-11.0$ & $5.0(1.5)$ & $5.5(0.9)$ & $5.7(1.4)$ & $7.0(1.4)$ & $6.2(1.0)$ & $6.7(1.3)$ & $5.3(1.4)$ & $5.3(1.2)$ \\
\hline Platelets & $150-400$ & $197(47)$ & $212(39)$ & $233(63)$ & $243(60)$ & $263(48)$ & $236(40)$ & $223(62)$ & $214(43)$ \\
\hline
\end{tabular}

Measurement units for haematological indices and indices of muscle damage and hepatic and renal function; sodium (mmol/1), potassium (mmol/l), urea (mmol/l), creatinine ( $\mu \mathrm{mol} / \mathrm{l}), \gamma$-glutamyl transferase $(\mathrm{GGT} ; \mathrm{U} / \mathrm{l})$, alkaline phosphatase (AP; U/l), alanine aminotransferase (ALT; U/l), albumin $(\mathrm{g} / \mathrm{l})$, total bilirubin $(\mu \mathrm{mol} / \mathrm{l})$, creatine kinase $(\mathrm{CK} ; \mathrm{U} / \mathrm{l})$, haemoglobin $(\mathrm{Hb} ; \mathrm{g} / 100 \mathrm{ml})$, white blood cells $\left(\mathrm{WBC} ; \times 10^{9} / 1\right)$, platelets $\left(\times 10^{9} / 1\right)$.

${ }^{\star} \mathrm{p}<0.05, \mathrm{tp}<0.01$, and $\neq \mathrm{p}<0.001$ indicate significant differences between the values before (Pre) and after (Post) supplementation within each group.

48 hours. Height and body mass (in underwear) were recorded. Blood samples were taken at rest by venepuncture (using the Vacutainer system, from an antecubital vein of the left or right arm) after subjects had been seated for at least five minutes. Samples for clinical chemistry analyses were dispensed into plain tubes (containing no anticoagulant), and samples for haematological analysis were dispensed into tubes containing EDTA. Samples were subsequently analysed for indices of renal function (serum sodium, potassium, urea, and creatinine concentrations), hepatic function (serum $\gamma$-glutamyl transferase, alkaline phosphatase, and alanine aminotransferase activity, and albumin and total bilirubin concentrations), and indices of haematological function (haemoglobin concentration was measured and white blood cells and platelets counted). In addition, an index of muscle damage (serum creatine kinase activity) was measured in the groups assessed six weeks after acute supplementation and after the more chronic maintenance regimen. All analyses were by routine methods in use at the University Hospital, Queen's Medical Centre, Nottingham.
STATISTICAL ANALYSIS

Student's $t$ test was used to compare values determined before and after supplementation in each of the groups (paired), and to compare the changes between corresponding $\mathrm{Cr}$ and placebo groups (unpaired), using a commercially available computer software package (Microsoft Excel). Statistical significance was declared at $\mathrm{p}<0.05$.

\section{Results}

All subjects reported adherence to the experimental protocol and complete ingestion of the supplements. None reported any adverse effects throughout the period of the study.

EFFECTS OF A Cr LOADING DOSE REGIMEN Group mean data of all indices measured were within the normal range before, the day after, and six weeks after the loading regimen (table 2). On the day after $\mathrm{Cr}$ loading, there was no significant difference in any of the indices measured before $\mathrm{Cr}$ loading; however, moderate decreases were observed in serum urea and bilirubin concentrations of the placebo group. Although there were no differences in absolute concentrations, there was a significant between

Table 3 Normal range ${ }^{16}$ and mean (SD) values of haematological indices and indices of muscle damage and hepatic and renal function before and immediately after five days of creatine or placebo ingestion followed by an eight week Cr or placebo maintenance regimen in the presence and absence of exercise training

\begin{tabular}{|c|c|c|c|c|c|c|c|}
\hline \multirow[b]{2}{*}{ Clinical index } & \multirow[b]{2}{*}{ Normal range } & \multicolumn{2}{|c|}{$C r_{M A I N T+E X}$ group } & \multicolumn{2}{|c|}{$C r_{M A I N T}$ group } & \multicolumn{2}{|c|}{$P_{M A I N T+E X}$ group } \\
\hline & & Pre & Post & Pre & Post & Pre & Post \\
\hline Sodium & $135-145$ & $140(2)$ & $139(2)$ & $140(2)$ & $140(1)$ & $141(2)$ & $140(1)$ \\
\hline Potassium & $3.5-5.0$ & $3.9(0.2)$ & $4.1(0.2) \dagger$ & $3.9(0.2)$ & $4.1(0.3) \dagger$ & $3.9(0.3)$ & $4.2(0.2)$ \\
\hline Urea & $2.5-7.0$ & $3.6(0.7)$ & $3.6(0.8)$ & $4.2(0.7)$ & $3.8(0.4)$ & $4.3(0.6)$ & $3.6(0.8)$ \\
\hline Creatinine & $54-117$ & $69(6)$ & $86(15)^{\star}$ & $68(4)$ & $95(17)^{\star}$ & $78(9)$ & $72(5)$ \\
\hline GGT & $0-40$ & $19(5)$ & $21(4)$ & $19(5)$ & $20(4)$ & $41(54)$ & $31(28)$ \\
\hline $\mathrm{AP}$ & $30-110$ & $52(6)$ & $60(12) \dagger$ & $53(8)$ & $55(9)$ & $67(18)$ & $64(11)$ \\
\hline ALT & $5-40$ & $27(4)$ & $22(3)$ & $26(4)$ & $21(4) \dagger$ & $30(5)$ & $28(9)$ \\
\hline Albumin & $35-50$ & $40(2)$ & $43(2) \dagger$ & $40(3)$ & $44(3) \dagger$ & $41(3)$ & $43(2)$ \\
\hline Bilirubin & $5-17$ & $10(4)$ & $10(2)$ & $9(2)$ & $10(2)$ & $12(6)$ & $12(2)$ \\
\hline $\mathrm{CK}$ & up to 200 & $142(149)$ & $142(48)$ & $91(59)$ & $91(34)$ & $186(194)$ & $198(145$ \\
\hline $\mathrm{Hb}$ & $11.5-16.5$ & $12.2(1.0)$ & $12.2(0.8)$ & 12.3 & $12.8(0.8)$ & $13.3(1.0)$ & $13.2(1.1)$ \\
\hline WBC & $4.0-11.0$ & $5.9(0.6)$ & $6.2(1.2)$ & $6.5(1.3)$ & $6.8(1.5)$ & $6.7(1.4)$ & $6.0(0.6)$ \\
\hline Platelets & $150-400$ & $244(59)$ & $249(58)$ & $268(21)$ & $292(59)$ & $274(43)$ & $267(70)$ \\
\hline
\end{tabular}

Measurement units for haematological indices and indices of muscle damage and hepatic and renal function; sodium (mmol/l), potassium $(\mathrm{mmol} / \mathrm{l})$, urea $(\mathrm{mmol} / \mathrm{l})$, creatinine $(\mu \mathrm{mol} / \mathrm{l}), \gamma$-glutamyl transferase $(\mathrm{GGT} ; \mathrm{U} / \mathrm{l})$, alkaline phosphatase (AP; U/l), alanine aminotransferase (ALT; U/l), albumin $(\mathrm{g} / \mathrm{l})$, total bilirubin $(\mu \mathrm{mol} / \mathrm{l})$, creatine kinase $(\mathrm{CK} ; \mathrm{U} / \mathrm{l})$, haemoglobin $(\mathrm{Hb} ; \mathrm{g} / 100 \mathrm{ml})$, white blood cells (WBC; $\left.\times 10^{9} / 1\right)$, platelets $\left(\times 10^{9} / 1\right)$.

${ }^{\star} \mathrm{p}<0.05$ and $\dagger \mathrm{p}<0.01$ indicate significant differences between values before (Pre) and after (Post) supplementation within each group. 
group difference in the change in serum creatinine concentration over time $\left(\mathrm{Cr}_{\mathrm{LOAD}}, 24\right.$ (10) $\left.\mu \mathrm{mol} / \mathrm{l} ; \mathrm{P}_{\mathrm{LOAD}},-3(2) \mu \mathrm{mol} / \mathrm{l} ; \mathrm{p}<0.05\right)$. This difference was not evident six weeks after the completion of the loading dose $\left(\mathrm{Cr}_{\mathrm{LOAD}+6}, 2\right.$ (2) $\mu \mathrm{mol} / 1 ; \mathrm{P}_{\mathrm{LOAD}+6}, 3$ (2) $\left.\mu \mathrm{mol} / \mathrm{l} ; \mathrm{p}>0.05\right)$. Serum sodium and urea concentrations had increased in the $\mathrm{Cr}_{\mathrm{LOAD}+6}$ group six weeks after completion of Cr loading (table 2). The change in serum urea concentration with time was significantly different in the $\mathrm{Cr}_{\mathrm{LOAD}+6}$ group compared with its placebo group $\left(\mathrm{Cr}_{\mathrm{LOAD}+6}, 1.2(0.3) \mathrm{mmol} / \mathrm{l}\right.$; $\left.\mathrm{P}_{\text {LOAD }+6,},-0.4 \quad(0.2) \quad \mathrm{mmol} / \mathrm{l} ; \mathrm{p}<0.001\right)$. A moderate decrease in serum albumin concentration was observed in the $\mathrm{P}_{\mathrm{LOAD}+6}$ group.

EFFECTS OF A Cr MAINTENANCE DOSE REGIMEN Group mean data of all indices measured were within the normal range before the $\mathrm{Cr}$ loading regimen and on the day after the maintenance regimen was completed (table 3). Small to moderate increases in serum potassium, creatinine, and albumin were observed in both groups receiving Cr. In addition, there was a small decrease in alanine aminotransferase concentration in the $\mathrm{Cr}_{\text {MANT }}$ group and an increase in alkaline phosphatase in the $\mathrm{Cr}_{\text {MAINT+EX }}$ group. There was a significant decrease in serum urea concentration in the $P_{\text {MAINT+EX }}$ group. The changes in serum creatinine concentration over time in the groups receiving $\mathrm{Cr}$ were significantly different from those in the placebo group ( $\mathrm{Cr}_{\text {MAINT }}, 26$ (6) $\mu \mathrm{mol} / \mathrm{l} ; \mathrm{Cr}_{\text {MAINT+EX }}, 17$ (4) $\mu \mathrm{mol} / 1 ; \mathrm{P}_{\text {MAINT+EX }},-6$ (3) $\mu \mathrm{mol} / 1 ; \mathrm{p}<0.001, \mathrm{p}<0.01$ respectively).

\section{Discussion}

We believe that this is the first detailed information to be reported on the effects of short term (20 g/day for five days) and more chronic ( $3 \mathrm{~g} /$ day for 56 days) Cr supplementation on a range of some haematological indices and indices of hepatic, muscle, and renal function, in young healthy adults. Information on some of these indices in older adults (older than 51) during eight weeks of Cr supplementation has been published in abstract form, ${ }^{17}{ }^{18}$ while more recent work has reported some clinical chemistry indices in male athletes ingesting $\mathrm{Cr}$ for 28 days, ${ }^{19}$ and renal responses in healthy men after short term supplementation. ${ }^{20}$ In none of these reports were adverse responses reported. Data from blood samples taken before supplementation, on the day after, and six weeks after an established $\mathrm{Cr}$ loading dose regimen, and after a subsequent eight week maintenance dose of 3 $\mathrm{g}$ /day have been examined in this study. Mean concentrations of all indices were well within the normal range ${ }^{16}$ at all times.

Creatinine has been established as the sole end product of $\mathrm{Cr}$ degradation, being formed non-enzymatically in an irreversible reaction..$^{22}$ As skeletal muscle is the major store of the body $\mathrm{Cr}$ pool, ${ }^{10}$ it is therefore the main site of creatinine production. In normal healthy people, plasma creatinine concentration is dependent on total muscle mass, ${ }^{23}$ thus daily renal creatinine excretion is relatively constant in a given individual, but can vary between individuals. ${ }^{24}$ In the present study, serum creatinine concentration on the day after Cr loading was within the normal range and was not significantly higher than that before supplementation. However, the relative change in concentration over time was significantly greater in the $\mathrm{Cr}_{\mathrm{LOAD}}$ group than in the placebo group. This difference in the change in serum creatinine concentration merely reflects an increased rate of muscle creatinine formation as a result of the dietary induced increase in muscle Cr stores, and has been reported previously, together with a parallel increase in urinary creatinine excretion. ${ }^{8}$ Six weeks after discontinuation of $\mathrm{Cr}$ loading, there was no indication of an elevated serum creatinine concentration. Muscle TCr will have returned close to the level found before supplementation by this time, ${ }^{8}$ as will have renal creatinine excretion. Maintaining elevated muscle $\mathrm{Cr}$ concentration by ingesting $3 \mathrm{~g} \mathrm{Cr}$ a day after $\mathrm{Cr}$ loading increased serum creatinine concentration above that seen before supplementation. However, these concentrations were again within the normal range and, as outlined above, were probably attributable to the increase in muscle $\mathrm{Cr}$ concentration.

We suggest that the increase in serum urea six weeks after the Cr loading regimen is of little clinical significance and unlikely to be a direct result of $\mathrm{Cr}$ supplementation. This contention is supported by the lack of any difference in serum urea concentration on the day after a $\mathrm{Cr}$ loading regimen and after more chronic supplementation with and without training.

Serum sodium concentration was increased six weeks after $\mathrm{Cr}$ loading. However, the absence of any similar change on the day after the end of supplementation suggests that this was unlikely to be due to supplementation, and the magnitude of the change would be expected to be of little clinical significance. Similarly, the increase in serum potassium concentration after chronic $\mathrm{Cr}$ supplementation was small and unlikely to be of clinical significance.

All hepatic function indices were within the normal limits before and after creatine loading. The changes observed in serum alkaline phosphatase $\left(\mathrm{Cr}_{\text {MAINT+EX }}\right)$ and alanine aminotransferase $\left(\mathrm{Cr}_{\text {MAINT }}\right)$ activity and albumin $\left(\mathrm{P}_{\mathrm{LOAD}+6}\right.$, $\left.\mathrm{Cr}_{\text {MAINT+EX }}, \mathrm{Cr}_{\text {MAINT }}\right)$ and bilirubin $\left(\mathrm{P}_{\text {LOAD }}\right)$ concentrations with time were all marginal and occurred in both directions. We suggest that these changes are unlikely to be of clinical significance and probably unrelated to the experimental protocol.

The haematological indices measured were unchanged by the supplementation protocols. Serum creatine kinase activity, an accepted marker of muscle damage, was unchanged six weeks after acute $\mathrm{Cr}$ supplementation, nor was it changed after more chronic supplementation in the presence and absence of resistance training. This latter finding is of interest, as anecdotal comments have linked $\mathrm{Cr}$ supplementation to the development of muscle cramps and muscle-tendon injury during or after exercise. ${ }^{11}$ 
In the present study, there were no reports of muscle cramping or injury.

In conclusion, no clinically significant changes in the haematological indices measured, nor in indices of muscle damage or hepatic and renal function, were observed after acute Cr loading or eight weeks of lower dose maintenance ingestion. The present data therefore suggest that there is no obvious risk to health of ingesting creatine supplements. Indeed, the 2-3 g a day maintenance dose of $\mathrm{Cr}$ currently advocated to maintain muscle $\mathrm{Cr}$ concentration after $\mathrm{Cr}$ loading ${ }^{8}$ is similar to the amount of $\mathrm{Cr}$ used daily by the body and could be partly achieved from meat and fish ingestion.

The authors wish to thank Ms Elizabeth Simpson of the School of Biomedical Sciences and the staff of the Departments of Clinical Chemistry and Haematology at the University
Hospital, Queen's Medical Centre, Nottingham for their Hospital, Queen's Medical Centre, Nottingham for their technical support. This research was supported by the Def

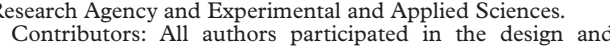
execution of the study protocol, discussed the interpretation of the findings, and contributed to the paper. T R participated in data collection, statistical analysis, and writing of the paper. D S participated in data collection, statistical analysis, and writing of the paper. A C participated in data collection and edited the paper. G S participated in data collection and edited the paper. $\mathrm{PG}$ initiated the research and edited the paper. $\mathrm{P} \mathrm{G}$ will act as guarantor.

1 Greenhaff PL, Casey A, Short AH, et al. Influence of oral creatine supplementation on muscle torque during repeated bouts of maximal voluntary exercise in man. Clin $\mathrm{Sci}$ 1993;84:565-71.

2 Gordon A, Hultman E, Kaijser L, et al. Creatine supplementation in chronic heart failure increases skeletal muscle creatine phosphate and muscle performance. muscle creatine phosphate and
Cardiovasc Res 1995;30:413-18.

3 Balsom PD, Ekblom B, Soderlund K, et al. Creatine supplementation and dynamic high-intensity intermittent exermentation and dynamic high-intensity in
cise. Scand 7 Med Sci Sports 1993;3:143-9.

4 Earnest CP, Snell PG, Rodriguez R, et al. The effect of creatine monohydrate ingestion on anaerobic power indices, muscular strength and body composition. Acta Physiol Scand 1995;153:207-9.
5 Casey A, Constantin-Teodosiu D, Howell S, et al. Creatine ingestion favourably affects performance and muscle
metabolism during maximal exercise in humans. $A m \mathcal{F}$ metabolism during max

6 Rowbottom M. Fears over sport's new 'legal steroid'. The Independent 1998 Dec 8;sect A: 1 .

7 Harris RC, Soderlund K, Hultman E. Elevation of creatine in resting and exercised muscle of normal subjects by creatine supplementation. Clin Sci 1992;83:367-74.

8 Hultman E, Soderlund K, Timmons J, et al. Muscle creatine loading in men. $₹$ Appl Physiol 1996;81:232-7.

9 Green AL, Simpson EJ, Littlewood JJ, et al. Carbohydrate ingestion augments creatine retention during creatine feeding in humans. Acta Physiol Scand 1996;158:195-202.

10 Walker, J.B. Creatine: biosynthesis, regulation, and function. Adv Enzymol Relat Areas Mol Biol 1979;50:177-242.

11 Anon. Is creatine safe? Sports Medicine Digest 1998;20:93-5.

2 Pritchard NR, Kalra PA. Renal dysfunction accompanying oral creatine supplements. Lancet 1998;351:1252-3.

13 Koshy KM, Griswold E, Schneeberger EE. Interstitial nephritis in a patient taking creatine. $N$ Engl $f \mathrm{Med}$ 1999;340:814-15.

14 Harris N, Arthur C. Creatine: anatomy of a 'miracle' substance. The Independent 1998 Dec 8;sect A:3.

15 Green AL, Hultman E, Macdonald IA, et al. Carbohydrate ingestion augments skeletal muscle creatine accumulation during creatine supplementation in humans. Am $\mathcal{F}$ Physiol 1996;271:E821-6.

16 The MEDICINE Publishing Foundation. Normal values in medicine. Oxford: The Foundation, 1983.

17 Earnest C, Almada A, Mitchell T. Influence of chronic creatine supplementation on hepatorenal function. FASEB $\mathcal{F}$ 1996;10:4566

18 Almada A, Mitchell T, Earnest C. Impact of chronic creatine supplementation on serum enzyme concentrations. FASEB 7 1996;10:4567.

19 Kreider RB, Ferreira M, Wilson M, et al. Effects of creatine supplementation on body composition, strength, and sprint performance. Med Sci Sports Exerc 1998;30:73-82.

20 Poortmans J, Auquier H, Renaut V, et al. Effect of short-term creatine supplementation on renal responses in short-term creatine supplementation on
men. Eur f Appl Physiol 1997;76:566-7.

21 Fitch CD, Sinton DW. A study of creatine metabolism in diseases causing muscle wasting. F Clin Invest 1964;43:44452

22 Fitch CD, Shields RP, Payne WF, et al. Creatine metabolism in skeletal muscle. III. Specificity of the creatine entry process. F Biol Chem 1968;243:2024-7.

23 Heymsfield SB, Arteaga C, McManus C, et al. Measurement of muscle mass in humans: validity of the 24-hour urinary creatinine method. Am 7 Clin Nutr 1900;37:47894.

24 Fitch CD. Significance of abnormalities of creatine metabolism. In: Rawland LP, ed. Pathogenesis of human muscular dystrophies. Amsterdam: Exerpta Medica, 1977:328-40.

\section{Take home message}

Recently there have been some concerns that creatine supplementation may have adverse effects on health. This paper investigated the effect of acute and more prolonged creatine supplementation on some haematological indices and indices of hepatic, muscle, and renal function. The data presented provide evidence that there are no adverse effects of acute or more chronic creatine supplementation on any of the indices measured and suggest that that there is no obvious risk to health of ingesting creatine supplements at the recommended doses. 